\title{
The Teaching Reform of Animation Specialty in Universities under the Aesthetic Education Environment
}

\author{
Qingxue Gao \\ College of Media and Communications \\ Zaozhuang University \\ Zaozhuang, China
}

\begin{abstract}
Aesthetic education plays an active role in the development of modern education system and social culture. In essence, it prefers an emotional education, focusing on the promotion of aesthetic taste. In university teaching, although aes the tic education has made some connections, it is still a weak link. Based on the analysis of the new requirements of digital media for animation professionals, taking several courses of animation major as examples, the implantation and methods of aesthetic education in classroom teaching are discussed. The teaching reform plan adapted to aes the tic education environment is put forward in the article.
\end{abstract}

Keywords-Digital media; Animation; Aesthetic education; Teaching reform

\section{INTRODUCTION}

China's ministry of culture, ministry of education and other relevant departments have attached great importance to the development of China's animation industry and the development of education talents for many years. The scale of universities to carry out animation education has been rapidly expanded. On the development road of animation education, the animation talent training mode was constantly reformed and perfected, and the improvement of teaching quality was an urgent matter. The major of animation offered a large number of compulsory courses, aiming to enable students to master the basic methods of animation creation, cultivated students' practical ability and creative expression ability, and lays a good foundation for subsequent animation creation and employment. In many universities that offer animation courses, the teaching process of animation courses was monotonous. Theory was main, skill was secondary, and there were a lot of cases of ignoring the aesthetic education. How to better integrate aesthetic education into animation teaching class and improve students' leaming initiative and knowledge digestion rate is a problem worth studying for animation teachers in many universities.

\section{AESTHETIC EDUCATION REQUIREMENTS FOR ANIMATION MAJORS}

\section{A. The Professional Abi lity of Animation Major Students}

Business ability, innovation ability and so on belong to the category of professional ability. The development of media makes digital media the most influential media form at present, which puts forward higher requirements for the cultivation of animation talents. The traditional animation teaching education is affected. The current situation is that, first of all, in the universities offering animation majors, a large part of them focus too much on teaching $2 \mathrm{~d}$ and $3 \mathrm{~d}$ animation courses and ignore the teaching method combining practice and theory, which makes students fail to combine the knowledge and software skills well in skill creation. Take sports photography lens in animation audio-visual language as an example, motion photography is also called motion photography. The camera is shot in different forms of motion, such as push, pull, shake, move, heel, sway, up and down, rotation and so on. In the process of motion photography, the generation of motion perspective depends on the motion of the object or the motion of the camera. When students create rotating lenses, the difficulty increases. The main reasons are as follows. First, in daily learning and creation, students focus on the operation of professional basic knowledge. They lack the production of indepth lens, and their basic skills are not solid enough, resulting in the creation of a single lens, less exciting shots. Second, students have less knowledge of motion perspective, and worry about making mistakes in animation creation, reducing or even denying the use of difficult shots such as orbit cam. In addition, the constant proliferation of technology and tools refreshes the meaning of digital media. It gradually formed a unique aesthetic culture[1].The trend of intelligent interaction between the development of technology and media is becoming more and more intense. This gave rise to new requirements for the aesthetic of media art. Learning knowledge is for better creation. The acceptance of new technology and the improvement of aesthetic character can encourage students to express more artistic animation works. The implantation of aesthetic education in classroom teaching of animation major is indispensable.

The improvement of professional basic ability is particularly important. The purpose of animation course 
teaching is to enable students to master the entire production process of animation, master the expression methods of various lenses, specific responsibilities of each work department, basic production methods and key original painting techniques. Train the students to connect the animation knowledge of previous categories in sequence, and guide them to collect data and write scripts at the same time. According to the specific requirements of scripts and shooting scenes, combine the animation knowledge of previous learning process to create animation short films independently. This requires animation major students to ask for both hand drawing and software skills. Master necessary hand drawing skills, including knowledge of human structure, physical painting and color setting. In addition, students also need to master the application skills of software such as Photoshop, Flash, and After Effect, 3DMAX, etc., to show their creativity to the maximum extent.

Mastering knowledge related to animation is an indispensable part of promoting students' comprehensive creative ability. In animation creation, the contents often involve history, geography, clothing and other fields. In the process of learning, animation major students can dabble in multidisciplinary knowledge. For example, learning the history of Chinese craft and art, you can know the craft type and production level of each period. Understand the national customs and geographical knowledge of various countries, and be able to find inspiration and stimulate creativity. Learning the knowledge of fashion design can be used for reference and application in creation, so that the works can better match historical facts. Reading reasoning can improve students' in-depth conception of script structure. All in all, the current animation production industry needs to cultivate more versatile talents.

\section{B. Requirements of Course Design in The Context of Aesthetic Education}

The teaching sequence and emphasis of animation courses should be reasonably arranged in consideration of the actual situation of students. For the group of students with relatively low overall level, manual drawing is the key. In teaching, the goal of professional training and teaching purpose should be agreed. For example, in the basic teaching of animation specialty, dynamic sketch can be strengthened in teaching; in basic design courses, graphic creative design courses can be added to highlight the interest of the courses and stimulate students' creative imagination. In the initial stage of software skills teaching, students can look at some excellent advertising designs at home and abroad in combination with art history. On the one hand, improve students' ability to appreciate excellent works; On the other hand, let students find inspiration from works and extract new methods of creation.

In addition, seeing more and practicing more is an important link to improve the skill level, and is the main method to improve students' aesthetic awareness. Strengthening the practice of skills can enable students to find and solve problems in continuous creation, so as to improve their creative ability. Therefore, in the course design, it is very desirable to arrange the course by focusing on the stage teaching and practicing after class. This way of arranging classes enables students to practice repeatedly in a concentrated period of time without forgetting what they have learned too quickly, which can also rapidly improve students' skills.

\section{ANIMATION TEACHING MODE ADAPTED TO AESTHETIC EDUCATION ENVIRONMENT}

\section{A. The Cultivation of Creative Thinking}

The key to developing creative thinking is to stimulate the imagination. The problem teachers often encounter in classroom teaching is that students don't know what to draw. With the animation character design as an example, the teacher can ask the students how to use simple geometric figures, such as circle, rectangle and triangle, to complete the creation of a character. This is an issue that involves professional foundations and imagination. The teacher can encourage the students to create in groups, and each group member can draw several strokes to complete the design of the final role. Furthermore, how to complete the design of a fruit and vegetable role? Teachers can instruct students to use digital media to collect design materials and guide them to use the method of stitching and adjusting the proportion of vegetables and fruits to complete creation. From the reflection of a fruit and vegetable character to how to create a perfect animation character, such creation process can stimulate students' imagination and desire for creation, and improve their interest in learning course knowledge. From the perspective of graphics and images, teachers can also guide students to process and design photos or video materials, complete new works through collage and post-special effects creation methods, and cultivate students' imagination and ability to comprehensively use knowledge.

The classification and fusion of knowledge is an indispensable part of creation. While reading relevant knowledge, students classify and absorb the knowledge and apply the knowledge to practice. Designing costumes of different styles for cartoon characters; Turn a scene in the surrounding environment into the scene design in the animation and so on. All of these learning methods can help students to integrate what they have learned.

In daily study, teachers guide students to pay attention to hot issues related to animation major, which is conducive to cultivating students' awareness of innovation. Teachers can integrate the hot issues of The Times into the classroom and guide students to create. For example, the characters in TV series are turned into cartoon characters for design; Make a short animation video of a phenomenon in recent news. All these teaching methods can encourage students to participate in the hot topics of The Times and bring the topics into creation.

\section{B. Aesthetic Education in the psychological Guidance and Construction of Students}

First, strengthen the interaction between teachers and students and students in the classroom. Students can be 
assigned to groups according to their learning interests, such as role design group, picture book creation group, etc., so as to strengthen the interaction and discussion among team members. In the classroom study, strengthens between the students the cooperation ability. Interaction and communication can integrate students' aesthetic consciousness together, which is also one of the methods to improve aesthetic taste. The student completes the sublimation of the design aesthetic feeling in the exchange and the interaction, thus promotes the creation.

Second, students are encouraged to participate in individual teacher projects. The project applied by teachers is undoubtedly a difficult experience and challenge for students. In the process of guiding students to participate in the subject, teachers can show their own knowledge and charm, from which students are spiritually infected and professionally supported. In addition, when students participate in teacher projects, they can understand the knowledge points that are difficult to be deepened in daily study, which is conducive to the effective combination of horizontal and vertical knowledge and the improvement of professional creative level.

Thirdly, understand the importance of vocational skills competition to students' creative ability. Vocational skill competition has a very good radiation effect. It is an important method to test students' professional creative ability based on post ability and oriented by employment. On the one hand, students can improve their interest in creation, promote students to form a good learning atmosphere, improve aesthetic taste and enhance practical ability. On the other hand, it can promote teaching and guide teachers' classroom contents. Teachers can adjust the course settings, optimize the course structure, and adjust the proportion of professional basic courses and practical courses according to the competition content. Vocational skills competitions can guide schools to pay attention to students' practical ability. The teaching and research office of the college may propose the competition scheme according to the current hot knowledge spot, organizes the student to carry on the competition. The competition sets up prizes for students with strong abilities. Through the competition, students can experience their own weaknesses. The students' practical ability has been confirmed, which is helpful for the re-creation and laying the foundation for the future internship and employment.

Fourth, standard teaching evaluation. Teaching evaluation can reflect teachers' teaching level, advantages, disadvantages and classroom effect. Students can judge the quality of teachers' teaching work by evaluating classes. As the direct teaching object, students are qualified to evaluate the quality of teachers' classroom teaching. To strengthen students' monitoring and evaluation of teachers' classroom, take students as the main evaluators, evaluate teachers' practical operation ability and professional ethics quality in class, and put forward valuable Suggestions, which urge teachers to timely adjust their individual teaching methods and have an important regulating effect on teachers' individual teaching quality.

\section{Aesthetic Education Requirements for Animation Teachers}

First, solid basic skills and skilled practice. The animation talent training program and the teacher's skill level should be closely aligned with the market demand, which requires the teacher to have solid basic skills and skilled practical ability. The current situation is that teachers who work on campus after graduation lack social practice experience. Teachers teach students unitary and outdated knowledge, ignoring students' future employment problems. It is necessary for teachers engaged in professional teaching of animation to participate in social practice related to animation and improve their comprehensive ability through social practice experience.

Second, the effective combination of expanding horizon and interdisciplinary. Animation major is a comprehensive subject, which covers film, art and other aspects, and can be used interchangeably with many disciplines, with a wide range of applications. It is helpful for teachers to improve their comprehensive quality and have more confidence in classroom teaching. Colleges and universities can add a series of lectures, and invite industry experts and senior technicians from enterprises to come, so that students can timely understand the latest industry trends and enterprise training objectives. In addition, teachers can actively participate in training programs in the animation or design company, real-time understanding of the latest industry trends, trends, employment information and so on. On the one hand, it can strengthen professional ability; on the other hand, from a long-term perspective, it can timely modify the animation talent training program according to the industry demand, and effectively assist the construction and management of animation specialty in universities.

\section{CONCLUSION}

The development and utilization of new ideas and new media make the existing teaching mechanism need to adjust the teaching thinking timely. Animation curriculum design needs innovation. Aesthetic education is a new trend in line with current cultural and social development. Teachers attach great importance to aesthetic education in the teaching process. Under the influence of aesthetic education, students' enthusiasm for learning and creation will be effectively mobilized. Aesthetic education can not only make the classroom more vivid, interesting, stimulate students' creativity, but also promote the development of Chinese animation education and cultivate more interdisciplinary talents.

\section{REFERENCES}

[1] Y. Li. "Media aesthetic culture in the context of digital media”. Beijing, vol.1, pp. 1, July2014.

[2] J.H. Yang. "Study on the teaching reform of animation specialty in colleges and universities," Art And Design (Theory), Vol. 7,pp.149151,2010.(In Chinese)

[3] L. Xia. "On the reform and innovation of advertising design teaching in the new media era,” Art Education Research, Vol. 23,pp.95-97,2013.(In Chinese) 
[4] K. Chen. "Research on the teaching reform of integrating innovation and entrepreneurship practice -- taking the animation specialty of guangzhou university as an example," Art Education Research, Vol. 15,pp.165,2015.(In Chinese)

[5] J. Ma. "Environmental art design teaching reform in the information age,” Journal of Shaoguan College, Vol. 1,pp.150-152,2011.(In Chinese)
[6] L. Yang. "The present situation and reform of environmental art design teaching in the information age," The Mass of Literature and Art, Vol. 12,pp.251-252,2015.(In Chinese)

[7] Y.H. Han. "Teaching reform of animation specialty hand-drawing course in colleges and universities," Art Education Research, Vol. 6,pp.131,2012.(In Chinese) 